\title{
SIMULATION MODEL IN TRNSYS OF A SOLAR HOUSE FROM BRAŞOV, ROMANIA
}

\author{
C. Şerban ${ }^{1}$, E. Eftimie ${ }^{1}$ and L. Coste ${ }^{1}$ \\ ${ }^{1}$ Department of Renewable Energy Systems and Recycling \\ Transilvania University of Braşov \\ B-dul Eroilor, 29, 500036 Braşov (România) Phone/Fax number: +0040 268412921 , \\ e-mail: cristina.serban@unitbv.ro,eftimiem@unitbv.ro, andreea.coste@unitbv.ro
}

\begin{abstract}
Energy consumption in buildings is a large share of the world's total end use of energy. Residential and commercial buildings require approximately $35 \%$ of the end use of energy, in addition to this energy is used for buildings also in the industry. In this context the paper proposes the energetically analysis for a small-scale modern station, providing solar heat to a solar house with 2 floors, located in the city of Braşov, România. The paper describes the location, size and thermal regime of the solar house; there are also presented the heating system facility and equipment components, designed for the solar house located in Transilvania University Campus. Based on the achieved simulations it is shown that compared to the ordinary control the energetically-based control provides remarkable advantages and savings concerning the auxiliary heating energy. This result should be valid for any systems similar to the particular one in Braşov.
\end{abstract}

\section{Key words}

Building energy system simulation, TRNSYS, smallscale system, energetic analysis, dynamic simulation.

\section{Introduction}

Energy consumption in buildings represents a large share of the world's total end use of energy. Residential and commercial buildings require approximately $35 \%$ of the end use of energy, in addition to this energy is used for buildings also in the industry. Globally, buildings account for close to $40 \%$ of total end use of energy. Given the many possibilities to substantially reduce buildings' energy requirements, the potential savings of energy efficiency in the building sector would greatly contribute to a society wide reduction of energy consumption. By reducing buildings' energy consumption, a nation can reduce dependency on imported energy and strengthen its strategic position.

Moderation of energy-end use in buildings will also reduce greenhouse gas emissions and pollution produced by the combustion of fossil fuels. This environmental benefit appears on two scales, local and global. Because much of buildings' demand for energy requires local energy combustion in individual heating systems or district heating, reduced energy demand improves air quality at the local level. In particular in developing countries a reduced demand for energy requires fewer power plants, thereby delaying or obviating the construction of new generation and grid capacity and enabling communities to devote public funds elsewhere. Given the potential scale of energy savings across the building sector, reduced demand for energy and fossil fuels can substantially contribute to a nation's compliance with domestic or supranational targets for the reduction of greenhouse gas emissions [1].

Economic strategy of sustainable development clearly requires the promotion of energy efficiency and the rational use of energy at national level. Specific consumptions of heat and hot water in România amounts to approximately double compare with those in European Union countries, as a direct consequence the pollutant emissions are higher.

The specific actual situation in România requires the introduction of government policy priorities, the policy of energy efficiency at wide scale. Due to the strong decline of internal hydrocarbons resources, and in the perspective of economic growth, it becomes obvious that, if we maintain the current usage of energy, energy import dependency will increase, further aggravating the external deficit, which will lead to the increase of external debt.

It is emphasized that the annual energy consumption of a building, regardless of its intended use, thermal energy for heating and hot water consumption represents the main annual energy consumption by about $75 \%$. For the overall residential buildings in România, the efficiency of the supply for heating, hot water and cooking is only $43 \%$ of the amount of heat provided by the sources; for Bucharest, it is of $63 \%$, but still unacceptably low. 


\section{Functional and constructive description of the building}

The Solar House (Figure 1, built between 2005 - and 2007) is a building situated on Transilvania University Campus in Braşov, Romania designed to study solutions for construction high efficiency buildings. Its optimized architectural form allows the movement of the air through natural ventilation. The two heated floors (first floor $90 \mathrm{~m}^{2}$ second floor $100 \mathrm{~m}^{2}$ ) provide the thermal comfort by using passive solar radiation at low temperature for the total building area $\left(250 \mathrm{~m}^{2}\right)$.

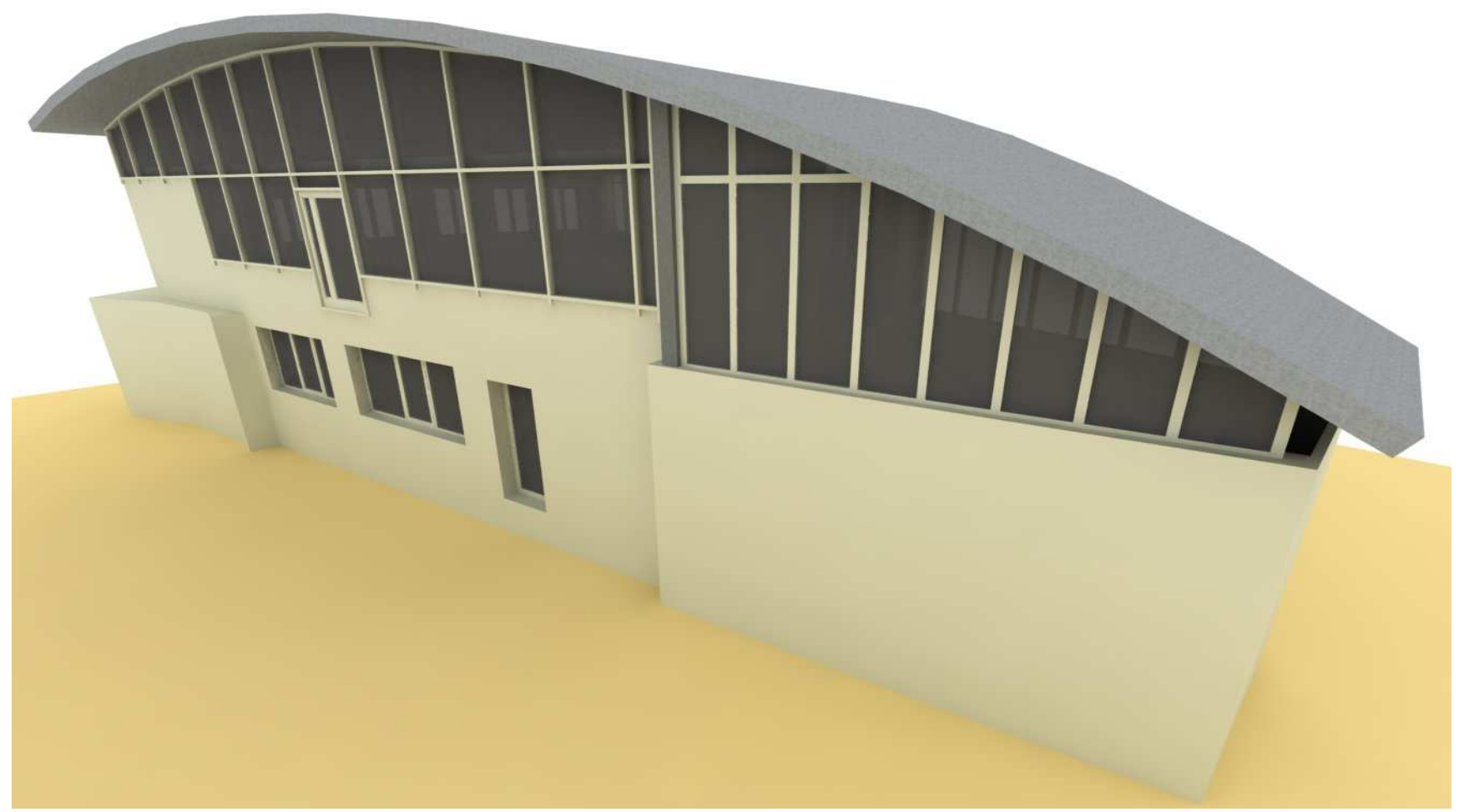

a) Perspective

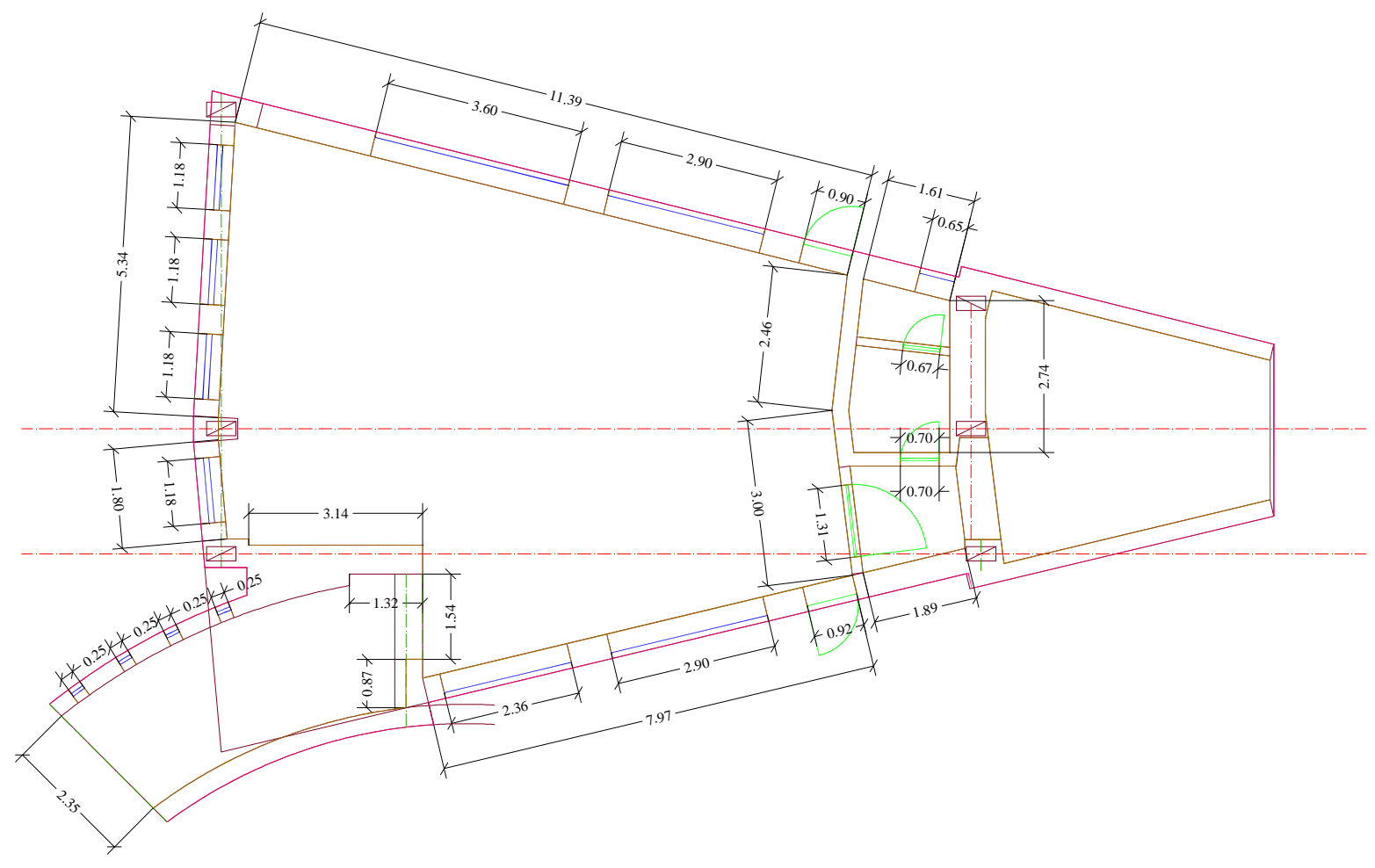

b) First floor

Fig. 1. Solar house in Braşov, România 
The same principle is taken into account by using radiant floor. The heating box is secured by a heat pump system with a horizontal ground-water type, the $10 \mathrm{~kW}$ installed on the plateau in the vicinity. Hot water demand is supplied by a system of six flat thermal collectors and three vacuum tubes, installed on the roof. The cooling and air conditioning, in the summer, will also be provided by the solar system. The excess hot water will be used in the gym's locker room which is posted directly under the Solar House.

The first floor is used as a work space for $12 \mathrm{PhD}$. Students and the second floor is used for official meetings and presentations.

\section{Water heating load}

For Braşov, the monthly inlet water temperature varies from $8-10{ }^{\circ} \mathrm{C}$ in the winter and $10-12{ }^{\circ} \mathrm{C}$ in the summer. The monthly mean temperatures for Brasov urban area are presented in Table I. The temperatures were measured with a Delta $\mathrm{T}$ weather station, positioned near the solar house, from October 2005 since present.

Table I. - Monthly mean temperatures in Braşov

\begin{tabular}{l|c}
\multicolumn{1}{c|}{ Month } & Temperature $\left[{ }^{\circ} \mathrm{C}\right]$ \\
\hline January & $-1,72$ \\
\hline February & 0,08 \\
\hline March & 4,51 \\
\hline April & 10,22 \\
\hline Mai & 14,84 \\
\hline June & 18,42 \\
\hline July & 20,30 \\
\hline August & 19,53 \\
\hline September & 14,29 \\
\hline October & 9,98 \\
\hline November & 4,44 \\
\hline December & $-0,23$ \\
\hline
\end{tabular}

In the present study, an averaged hot water consumption of $60 \mathrm{l}$ /day is considered, based on a close monitoring. The hot water consumption depends on the season of the year, time of the day and geographical parameters also of the nature of the work developed in the building [2].
The hourly distribution of hot water consumption in the solar house is presented in Figure 2.

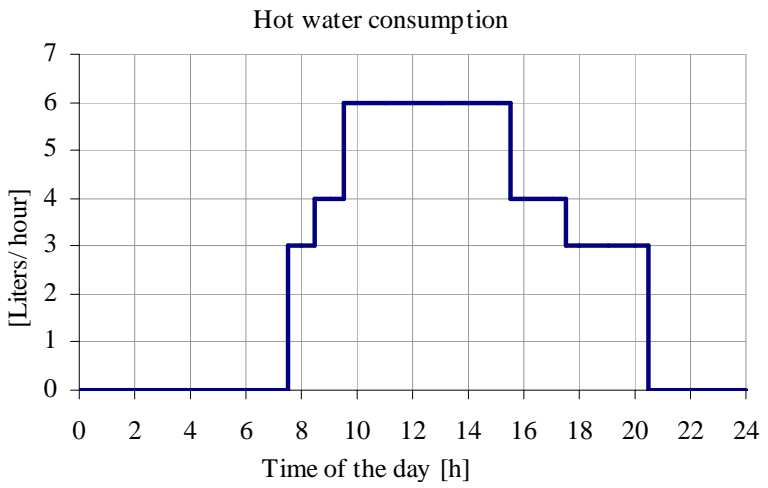

Fig. 2. Daily hot water consumption profile

\section{Description of the power generation system}

HVAC systems maintain a building's comfortable indoor climate through Heating, Ventilation and Air Conditioning (Cooling). These systems profoundly influence energy consumption in buildings. Without heating, cooling and ventilation systems there would be no energy consumption in the building, since it would be totally dependent on outdoor conditions.

The heat requirement of the building is acquired by a heat pump plant, operating after a bivalent scheme: radiant low temperature floor heating for rooms at level 1 and 2 of the building and domestic hot water preparation. The heat from the soil is extracted through collectors located on the platform area nearby. The capturing field is composed of $6 \times 100 \mathrm{~m}$ loops of pipe. The pitch of the loops is about $1 \mathrm{~m}$. It has been provided an expansion tank of 251 and a circulation pump on the primary circuit.

The secondary part of the installation comprises a heat accumulator of 3001 and two bivalent boilers of 10001. As an auxiliary source for peak loads a wall-mounted boiler of $11.8 \mathrm{~kW}$ has been provided. The other installation characteristics are presented in Table II.

Table II. - Characteristics of the installation

\begin{tabular}{l|l} 
Components & Characteristics \\
\hline DHW & Volume: $2 \times 1000$ liters \\
\hline Heat pump & Ground source heat pump; heating power: $10 \mathrm{~kW}$ \\
\hline Boreholes & Number: $6 \mathrm{x} 100 \mathrm{~m}$ at $1.5-2 \mathrm{~m}$ depth \\
\hline Soil & Dry clay soil with specific extraction power of $\mathrm{q}_{\mathrm{E}}=20\left[\mathrm{~W} / \mathrm{m}^{2}\right]$ \\
\hline Heating/Cooling floor & $190 \mathrm{~m}^{2}$ \\
\hline Total building surface & $250 \mathrm{~m}^{2}$ \\
\hline
\end{tabular}

A simple scheme of the water circulation is presented in Figure 3. During the cold period (October - March), because the intensity of the solar radiation is low, the heat pump (A) will take over also the domestic hot water preparation and the heating of the building. In the summer (April- September) the solar collector system (B) will be mainly used for the domestic hot water preparation and the heat pump will be used for cooling the building, when necessary.

Having both, heat pump and solar collectors, the use of the auxiliary heater (wall-mounted boiler - C) is reduced 
to a minimum [3]. The auxiliary heater turns on only in the peak loads. The system produces domestic hot water stored in a bivalent tank (D) and water for space heating stored in tank $(\mathrm{E})$. The heated water in the tank (E) goes to the two low temperature radiant floors.

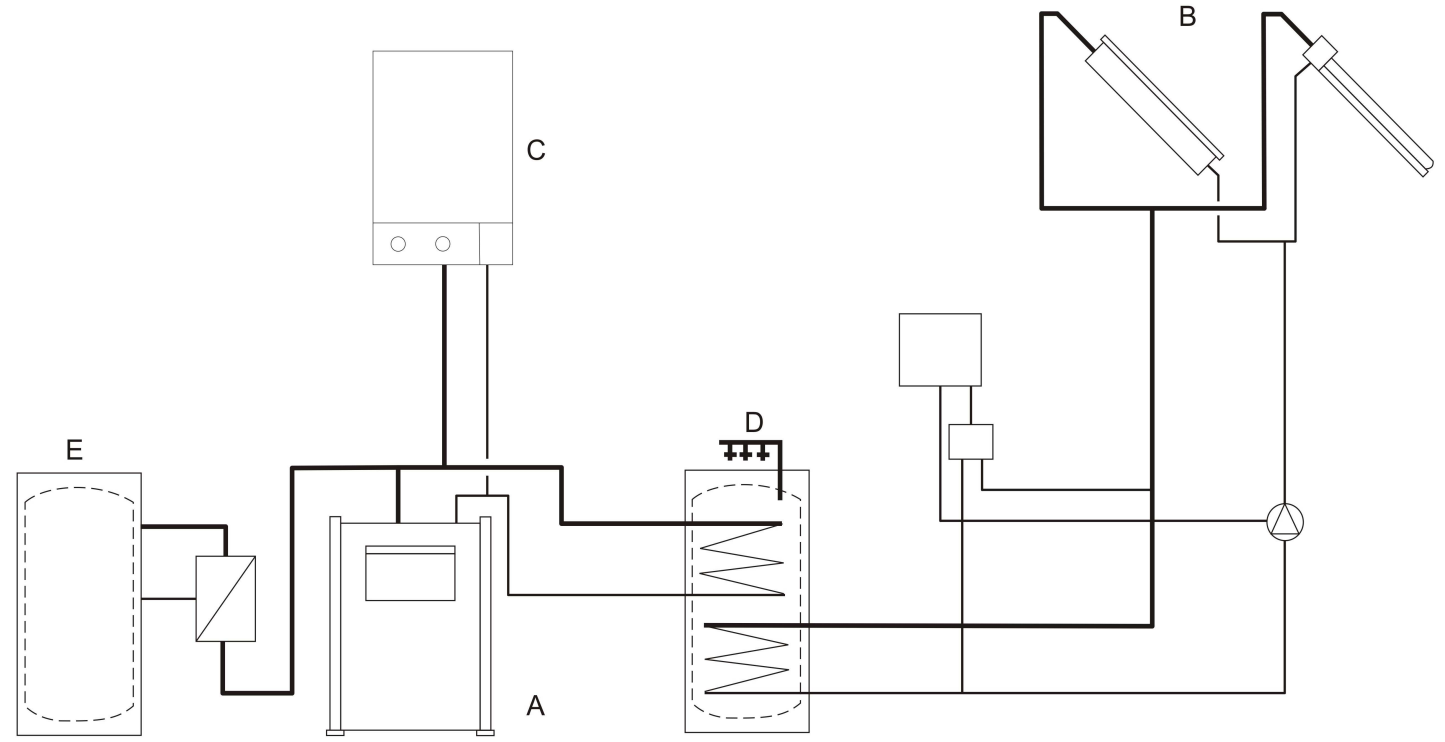

Fig. 3. Simple scheme of the installation

\section{Dynamic simulation of the system behavior}

TRNSYS is a complete and extensible simulation environment for the transient simulation of thermal systems including multi-zone buildings. It is used by engineers and researchers around the world to validate new energy concepts, from simple domestic hot water systems to the design and simulation of buildings and their equipment, including control strategies, occupant behavior, alternative energy systems (wind, solar, photovoltaic, hydrogen systems), etc. [4].

To calculate the thermal load for heating/cooling, ventilation or air conditioning of any building, appropriate climate information of the building location are needed (e.g. the sizing of the heating systems require information on climatic parameters, which give the extreme conditions which the installation must meet) [5].

Numerical simulations were carried out using TRNSYS software, one of the most important building energy simulation software, that is used by engineers and researchers around the world to validate new energy concepts, from simple solar domestic hot water systems to the design and simulation of buildings and their equipment, including control strategies, occupant behavior, alternative energy systems (wind, solar, photovoltaic, hydrogen systems), etc. The TRNSYS solar house HVAC system is represented in Figure 4.

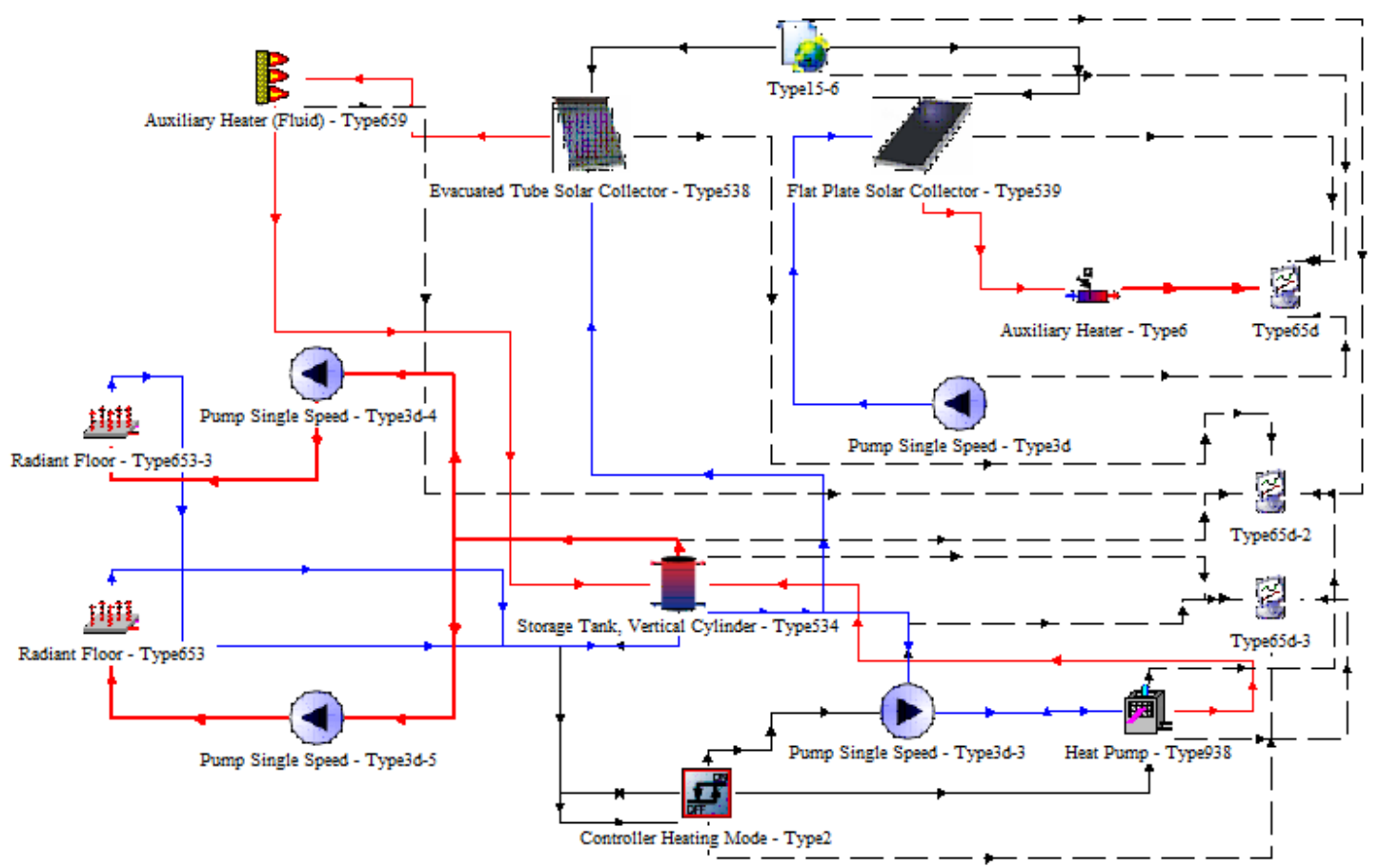

Fig. 4. TRNSYS model 

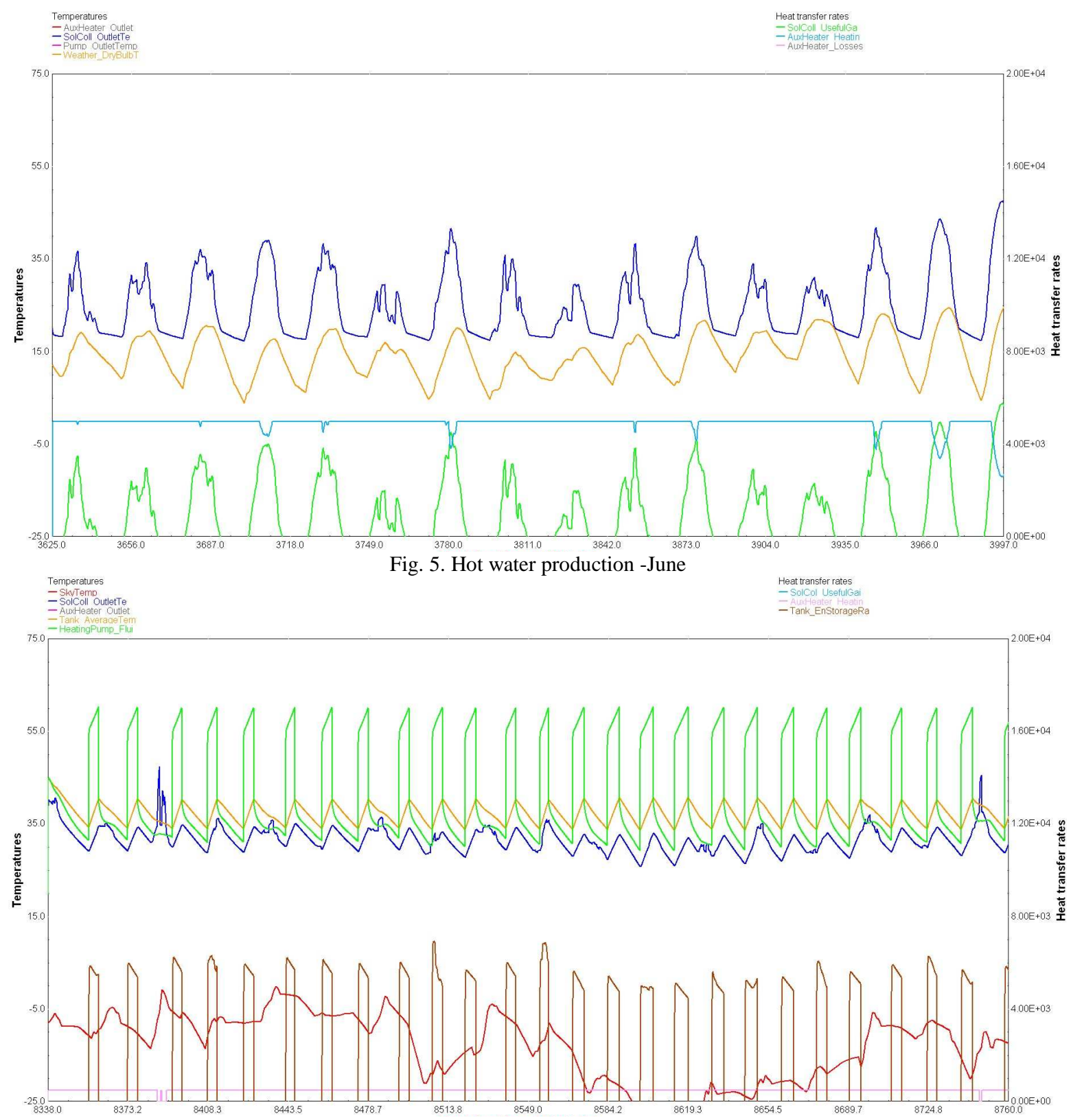

Fig. 6. Floor heating - December

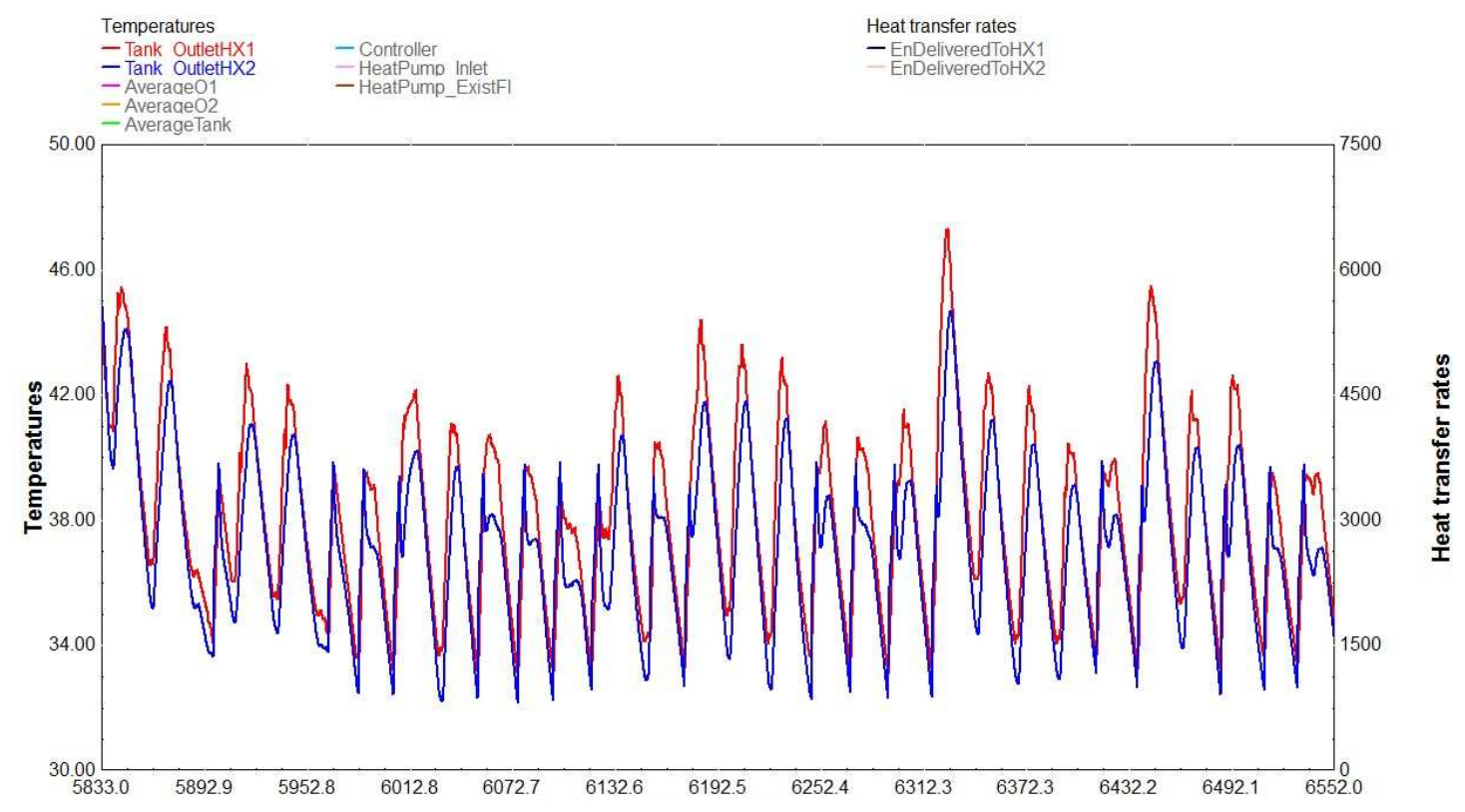

Fig. 7. Storage tank output temperatures - September 
At the next stage, the physically-based mathematical model of solar heating systems is proposed. The model is realized in TRNSYS 17 simulation environment which is well recognized and frequently-used in scientific researches of transient thermal processes. The model is flexible and can be easily adapted to a wide range of particular solar heating systems being a good tool for analysis and development [6].

Figure 5 presents the hot water production during the first two weeks of June. The heat pump is turned off, the domestic hot water being produced by the solar collector system. It can be observed that the solar collector outlet temperature varies from $10{ }^{\circ} \mathrm{C}$ in the morning, when the solar radiation is low, to $40{ }^{\circ} \mathrm{C}$ in the noon.

The heat pump outlet temperature variation can be observed in Figure 6. The simulation was performed for two weeks in December, when the ambient temperature drops below $0{ }^{\circ} \mathrm{C}$ and space heating is necessary. The desired indoor temperature was set to $21{ }^{\circ} \mathrm{C}$ to ensure a comfortable work environment. The solar collector outlet temperature is lower, due to the decreased solar radiation.

In September, the solar system still produces hot water but the heat pump is turned on, supplementing the hot water requirement when needed (Figure 7). The output temperature of the tank is set to $50{ }^{\circ} \mathrm{C}$.

\section{Conclusions}

The combination of renewable energies such as thermal solar energy and geothermal energy in a single system should make it possible to meet a residence's heating and hot water requirements, while guaranteeing a satisfactory level of comfort.
The objective of this work was to evaluate the goodness of the heating system using TRNSYS and to predict the long term energy performance of the entire system. The study is not complete.

\section{Acknowledgement}

This paper is supported by the Sectoral Operational Programme Human Resources Development (SOP HRD), financed from the European Social Fund and by the Romanian Government under the contract number POSDRU/88/1.5/S/59321 and POSDRU/6/1.5/S/.

\section{References}

[1] J. Lausten, Energy efficiency requirements in building codes, energy efficiency policies for new buildings, International Energy Agency, OECD/IEA France (2008).

[2] A. Hobbi, et al., Optimal design of a forced circulation solar water heating system for a residential unit in cold climate using TRNSYS, Solar Energy 83 (2009) pp. 700714.

[3] V. Trillat-Berdal, et al., Experimental study of a groundcoupled heat pump combined with thermal solar collectors, Energy and Buildings 38 (2006) pp. 1477-1484.

[4] S.A. Klein, et al., TRNSYS 16: A Transient System Simulation Program, University of Wisconsin Solar Energy Laboratory, Madison USA (2006).

[5] M.A. Munteanu, The use of renewable energy sources in passive and active systems, Technical University 'Gheorghe Asachi' in Iaşi, Faculty of Construction and Installation, Iasi (2010).

[6] R. Kicsiny, Energetically-Based Control for Solar Heating Systems, Scientific Bulletin of Polytechnic University of Timişoara, Transaction on Mechanics, România (2009), pp. 59-66. 